\title{
Performance, Characterization and Evaluation of Axial Flow Turbine Engine
}

\author{
Avwunuketa, A.A. ${ }^{1}$ Bonet, M. ${ }^{2}$ Adamu, M.L. ${ }^{3}$ Haruna, U. ${ }^{3}$ Fadenipo. O.T. ${ }^{3}$ \\ ${ }^{1-3}$ Aircraft Engineering Department, \\ Faculty of Air Engineering, \\ School of Postgraduate Studies \\ Air force Institute of technology, \\ Kaduna Nigeria. \\ ${ }^{2}$ Mechanical Engineering Department, \\ Nigerian Defence Academy, \\ Kaduna Nigeria
}

\begin{abstract}
This research paper mainly focuses on the performance, characterization and evaluation of the axial flow gas turbine engine used for aircraft applications. Attempt from previous researches were to increase the efficiency and work output of the turbine. To achieve further improvement in the efficiency, the turbine blades were subjected to a higher temperature. With the knowledge from material science and engineering, suitable materials were selected for the design of suitable blades that can withstand higher temperature without failure.
\end{abstract}

To achieve the efficient performance of the turbine, the hot gases from the combustor, are to be directed at a suitable angle at the entry to the turbine as well as exit from the turbine. This research work thoroughly focuses on how the blade configuration are designed to achieve the desired output.

Development of the axial flow gas turbine was hindered by the need to obtain both a high-enough flow rate and compression ratio from a compressor to maintain the air requirement for the combustion process and subsequent expansion of the exhaust gases. Design specifications were given, to provide a detailed understanding of axial flow turbine design. Values obtained were used to produce a graph that explained how turbine parameters vary.

Key Words: Axial, Blade, Combustor, Efficiency and Reaction Turbine.

\section{INTRODUCTION}

Gas turbine extracts power from the gas stream to drive shaft that is connected to propeller through a gearing system or electric generator and at the same time driving the compressor. Gas turbine are classified basically on the direction of flow such as axial flow gas turbine. Majority of gas turbines employed the axial flow type. The radial flow gas turbine can handle low mass flow than the axial flow, it is widely used in turbocharger of a reciprocating engines and in cryogenic industries. For low power, the axial flow turbine is more efficient, when mounted back-to-back with a centrifugal compressor.[1]

The choice of turbine type depends on the application, the radial turbine is capable of a higher

Pressure ratio per stage than the axial one. However, multi staging is very much easier to arrange with the axial turbine, so that large overall pressure ratios are not difficult to obtain with axial turbines [2]. The efficiency of an axial turbine is higher than the efficiency of an axial compressor, reason is that the fluid undergoes a pressure drop in axial turbine and pressure rise in axial compressor. The pressure drop in the turbine is sufficient to keep the boundary layer fluid generally well behaved, and separation problems that are often serious in compressors can be relatively easily avoided [2].

The axial flow type of gas turbine are used in aircraft gas turbine engine, industrial gas turbine engine and shipboard applications. The axial flow turbine consists of one or more stages located immediately to the rear of the engine combustion chamber [3]. 
Kinetic energy are extracted by the turbine from the expanding hot gas from the combustor, the kinetic energy are converted into shaft power to drive the compressor and engine accessories.

\subsection{CLASSIFICATION OF AXIAL FOW TURBINE}

- Impulse Turbine: In the impulse turbine, the gases are expanded in the nozzle and pass over to the moving blades (Rotors). The rotor convert the kinetic energy into mechanical energy and direct the gas flow to the next stage if there are multi-stage turbine or to exit it is a single-stage turbine.

- Reaction turbine: In the reaction turbine, the gases are expanded both in nozzle as well as in the rotor.

Figure 1.0 show the rotor of an axial turbine.

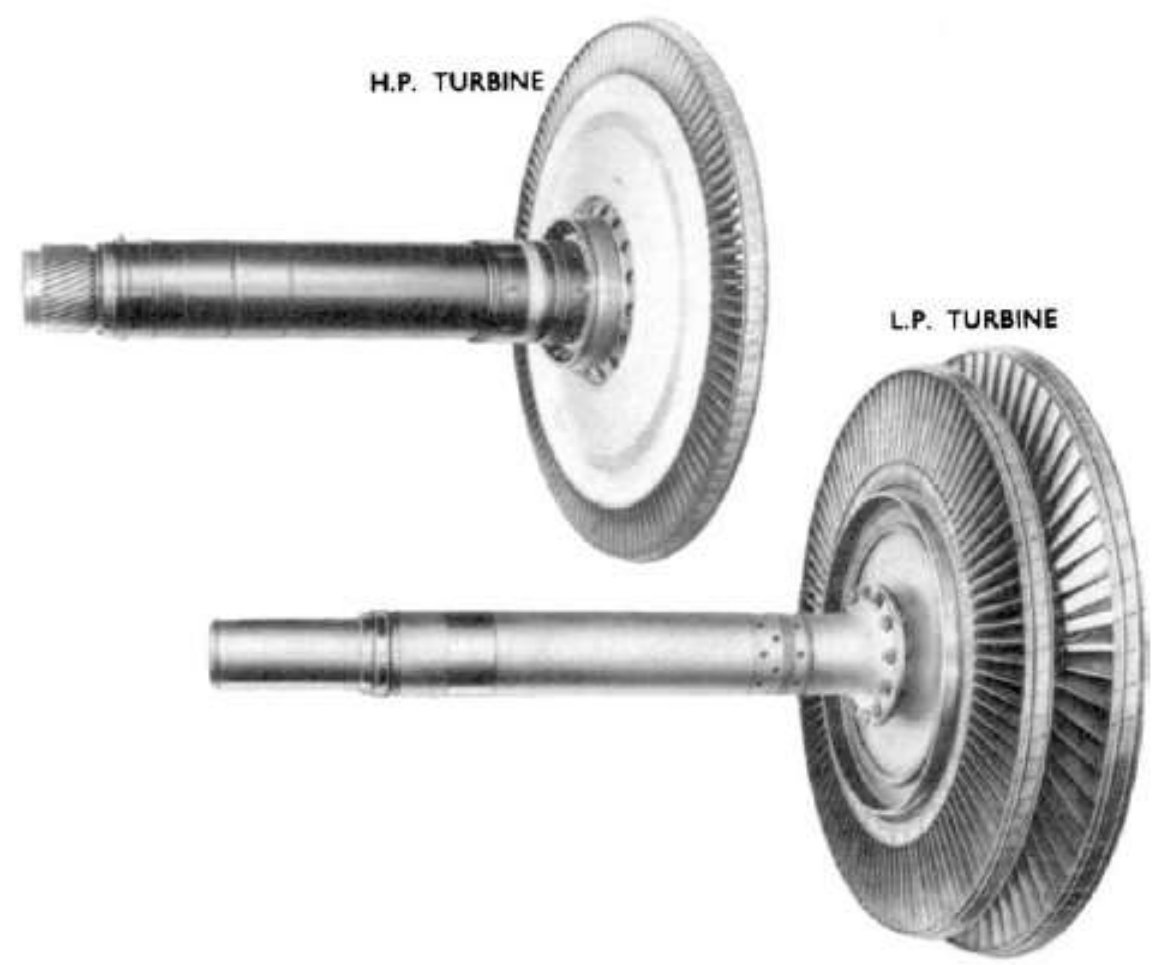

Figure 1.0 Axial flow Turbine Rotor [ 3]

Steam turbines are usually impulse or a mixture of impulse and reaction stages but the turbine for a gas-turbine power plant is a reaction type. Therefore the reaction stages are used where pressure drop per stage is low and also where the overall pressure ratio of the turbine is low, especially in the case of aircraft engine, which may have only three or four reaction stages [3]

\subsection{Axial turbine stage}

An axial turbine stage consists of a row of stationary blades called stators or nozzles, follow by a row of a moving blades called rotor. Due to to large pressure large pressure drop per stage in an axial turbine,

The nozzle and the rotor blades may be of increasing length to accomadate the expanding gases, and at the same time keeping the axial velocity uniform through the stage. Figure 1.1 show the stage of the axial turbine. 


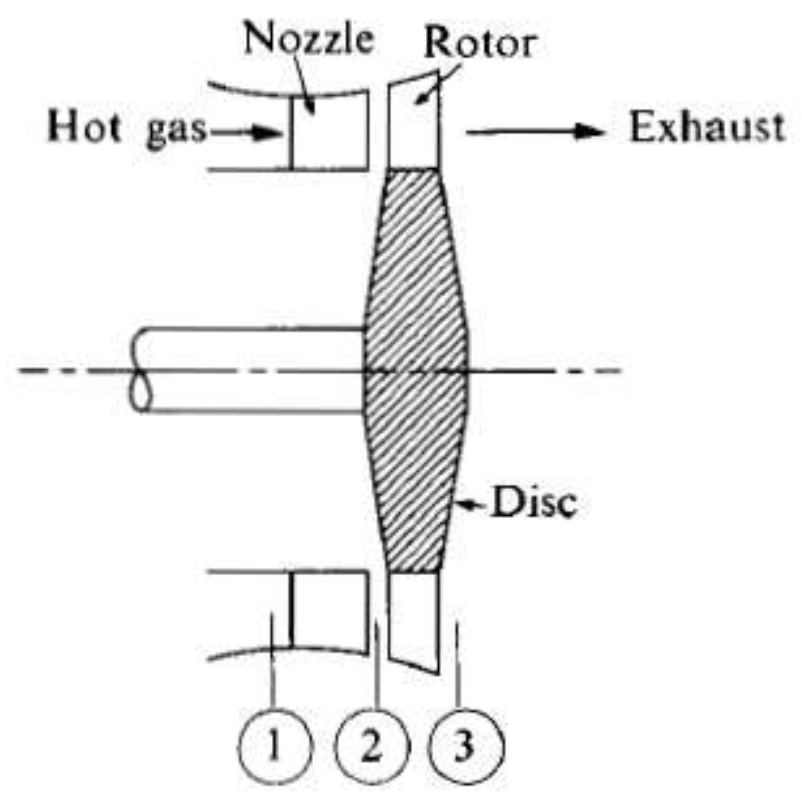

Figure 2.0 An axial Turbine [2]

\section{VELOCITY TRIANGLE}

Figure 2.2 show the velocity diagram of an axial turbine. The absolute velocity $C_{1}$ of the gas, making an angle of $\alpha_{1}$ enter the nozzle or stator blade. The gas leaves the stator blades with an absolute velocity of $C_{2}$ with an angle $\alpha_{2}$ with axial direction. $\beta_{2}$ will be the rotor inlet angle with velocity $V_{2}$ relative to the blade at inlet. $\beta_{2}$ and $V_{2}$ are obtained by subtracting the blade velocity $\mathrm{U}$ from the absolute velocity $C_{2}$. After the expansion of the gas, in the rotor blade passages, the gas exit with relative velocity of $V_{3}$ at an angle $\beta_{3}$. $V_{3}$ is slightly less than $V_{2}$ due to friction or equal $V_{2}$. But in reaction stage, $V_{3}$ is always greater than $V_{2}$ because part of the pressure drop willk be converted into kinetic energy in the moving blade.

The magnitude and direction of the absolkute velocity at exit from the rotor $C_{3}$ at angle $\alpha_{3}$ are found by the vectorialaddition of $\mathrm{U}$ to the rewlative velocity $V_{3}$. The swil angle is $\alpha_{3}$.

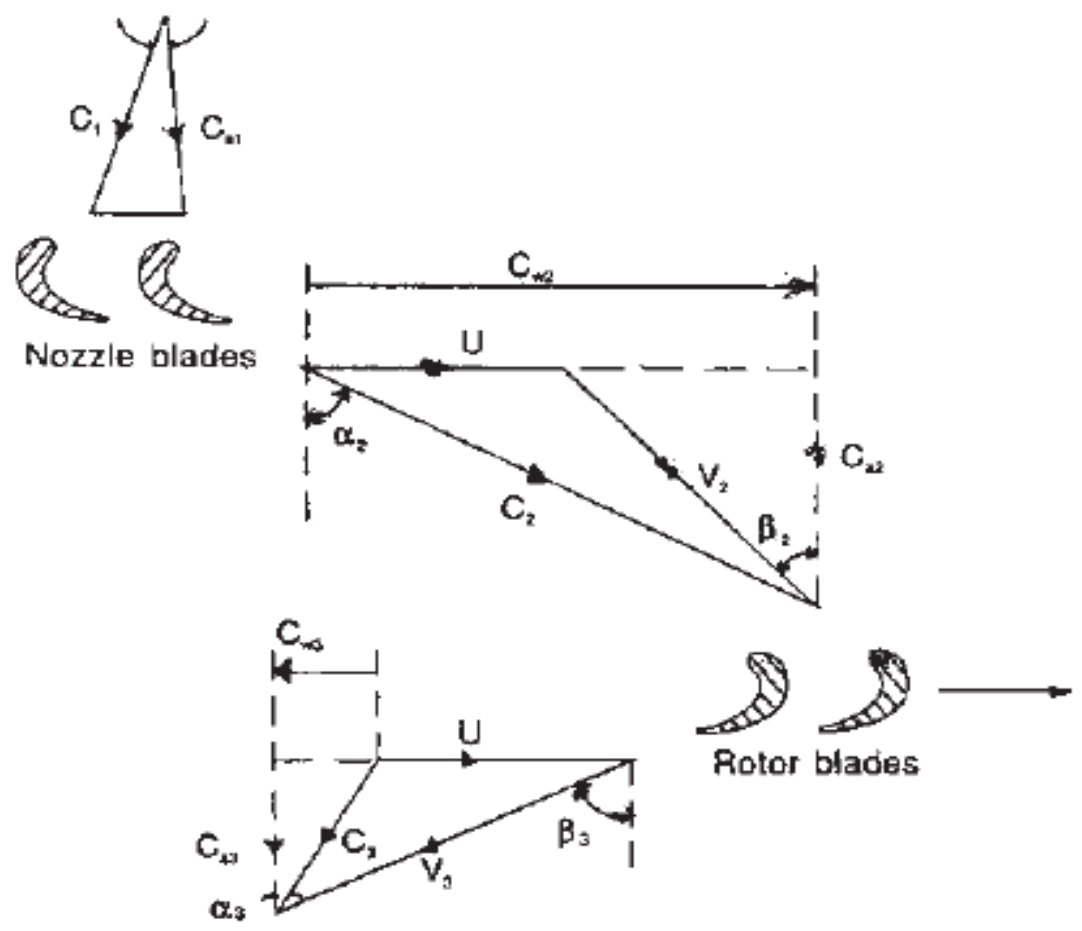

Figure 2.1 velocity triangles for an axial flow gas turbine 
The combine velocity triangle is shown in figure 3.0

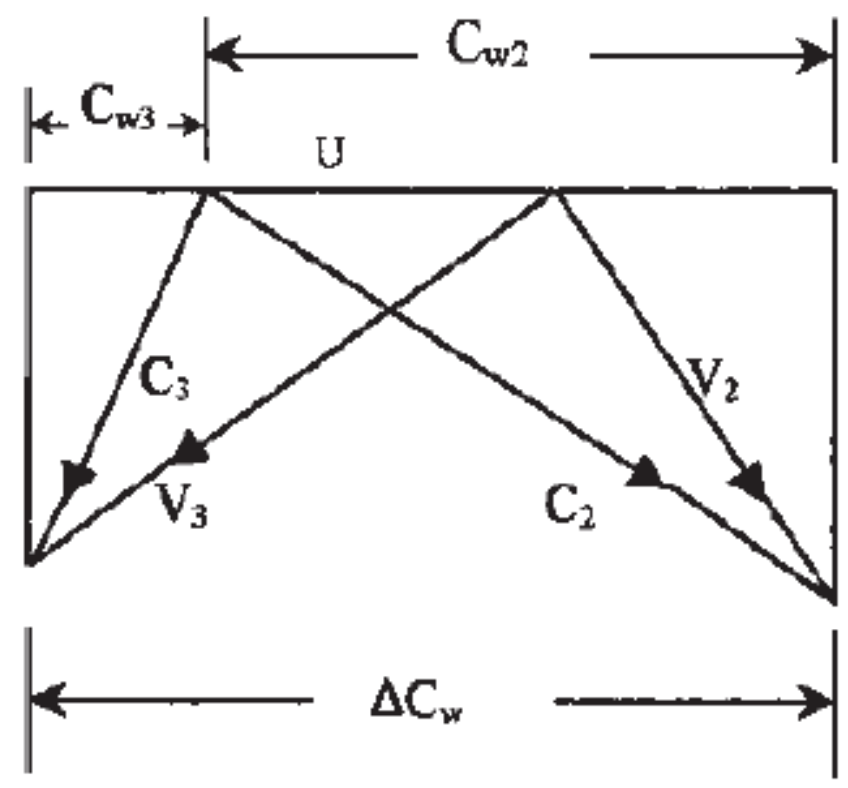

Figure 3.0 Combine Velocity Diagram

Work done by the gas, assuming unit mass flow is given by

$W_{T}=U\left(C_{w 2}+C w_{3}\right)$

From the velocity triangle in fig 2.2

$\frac{U}{C_{a}}=\tan \alpha_{2}-\tan \beta_{2}=\tan \beta_{3}-\tan \alpha_{3}$

$W_{T}=U C_{a}\left(\tan \alpha_{2}+\tan \alpha_{3}\right)$

Substituting equation 2 into equation 3

$W_{T}=U C_{a}\left(\tan \beta_{2}+\tan \beta_{3}\right)$

From steady flow energy equation (SFEE)

$W_{T}=c_{p} \Delta T_{o s}$

Where $\Delta T_{o s}$ is the stagnation temperature drop in the stage $c_{p}$ is the specific heat capacity at constant pressure $c_{p}=1.148 \mathrm{~kJ} / \mathrm{kgK}$

The stagnation pressure ratio of the stage $P_{01} / P_{03}$ is given by

$\Delta T_{0 s}=\eta_{s} T_{01}\left[1-\left(\frac{1}{P_{01 / P_{03}}}\right)^{\gamma-1 / \gamma}\right]$

Where $\eta_{s}$ is the isentropic stage efficiency based on stagnation or total temperature

$\eta_{t t}=\frac{T_{01}-T_{03}}{T_{01}-T^{\prime}{ }_{03}}$

The total-to-total stage efficiency is used when the exiting kinetic energy is utilized either in the next stage of the turbine or in a propelling nozzle. If the exiting kinetic energy from the exhaust is wasted, the total-to-static efficiency term is used.

$\eta_{t s}=\frac{T_{01}-T_{03}}{T_{01}-T^{\prime}}$

\section{BLADE- LOADING COEFFICIENT $(\psi)$}

The blade-loading coefficient is the ratio of the specific work of the axial turbineto the square of the blade velocity. It is used to express the work capacity of the stage.

$\psi=\frac{W_{T}}{\frac{U^{2}}{2}}$ 
$\psi=\frac{2 W_{T}}{U^{2}}$

Substitute equation (5) into equation (10)

$\psi=\frac{2 c_{p} \Delta T_{0 S}}{U^{2}}$

Substitute equation (4) into equation (11)

$\psi=\frac{2 C_{a}\left(\tan \beta_{2}+\tan \beta_{3}\right)}{U}$

\section{FLOW COEFFICIENT( $\Phi)$}

This is the ratio of inlet velocity to the blade velocity $\Phi=\frac{C_{a}}{U}$.

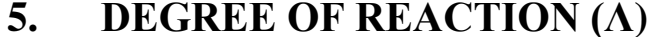

This is defined as

$\Lambda=\frac{\text { Enthalpy Drop in the Moving Blade }}{\text { Enthalpy Dropinthe stage }}$

$\Lambda=\frac{h_{2}-h_{3}}{h_{1}-h_{3}}$

$\Lambda=\frac{C_{a}}{2 U}\left(\tan \beta_{3}-\tan \beta_{2}\right)$

$\psi=2 \Phi\left(\tan \beta_{2}+\tan \beta_{3}\right)$

$\Lambda=\frac{\Phi}{2}\left(\tan \beta_{3}-\tan \beta_{2}\right)$

\section{DESIGN SPECIFICATION}

This is paper focus on the study and verification of various parameters obtained from the design calculations, that affect the performance of an axial flow turbine. For this paper, the single-stage axial flow turbine of free vorttex design is adopted with gas leaving the stage in axial direction.

- $\quad$ Turbine inlet temperature (TIT), $T_{01}$

$1200 k$

- $\quad$ Turbine inlet pressure (TIP), $P_{01}$

$18 \mathrm{bar}$

- Mass Flow

$25 \mathrm{~kg} / \mathrm{s}$

- Axial velocityat nozzle exit

$350 \mathrm{~m} / \mathrm{s}$

- Blade speed at mean diameter

$500 \mathrm{~m} / \mathrm{s}$

- Nozzle angle at mean diameter

$24^{\circ}$

- Overall pressure ratio

- Isentropic efficiency $\eta_{s}$

0.8

- Ratio of tip to root radius

1.8

- $C_{p g}$

$1.147 \mathrm{~kJ} / \mathrm{kgK}$

- $\gamma$

\subsection{The total Throat Area of the Nozzle}

$\frac{T_{C}}{T_{01}}=\frac{2}{\gamma+1}$

$T_{01}=1200 \mathrm{k}, \quad \gamma=1.33$

$\frac{T_{C}}{1200}=\frac{2}{1.33+1}$

$T_{c}=1030 \mathrm{~K}$

$\frac{P_{C}}{P_{01}}=\left[\frac{2}{\gamma+1}\right]^{\frac{\gamma}{\gamma-1}}$ 
$\frac{P_{c}}{18}=\left[\frac{2}{1.33+1}\right]^{\frac{1.33}{1.33-1}}=\left[\frac{2}{2.33}\right]^{4}$

$P_{c}=9.77 b a r$

Steady Flow Energy Equation

$T_{01}=T_{c}+\frac{V_{c}{ }^{2}}{2 C_{p g}}$

$\left.V_{c}=\sqrt{2 C_{p g}\left(T_{01}-T_{c}\right.}\right)$

$V_{c}=\sqrt{2 \times 1147(1200-1030)}$

$V_{c}=624.5 \mathrm{~m} / \mathrm{s}$

From equation of state

$\rho_{c}=\frac{P_{C}}{R T_{C}}$

$\rho_{c}=\frac{9.77 E 5}{287 \times 1030}$

$\rho_{c}=3.305 \mathrm{~kg} / \mathrm{m}^{3}$

$A=\frac{m}{\rho V_{C}}$

$A=\frac{25}{3.305 \times 624.5}$

$A=0.0121 m^{2}$

The throat areaof the nozzle is $12.1 \mathrm{~mm}^{2}$

6.2 The Nozzle efflux Angle at the Root and Tip.

$\alpha_{1}=$ Angle at any radius $r$

$\alpha_{1 m}=$ Angle at the design radius $r_{m}$

$\alpha_{1}, \alpha_{1 m}, r$, and $r_{m}$ are related by equation (25)

$\tan \alpha_{1}=\frac{r_{m}}{r_{1}} \tan \alpha_{1 m}$

$\frac{r_{t}}{r_{r}}=1.8$

$\frac{r_{m}}{r_{r}}=1.4$

$\tan \alpha_{1 r}=\frac{r_{m}}{r_{r}} \tan \alpha_{1 m}$

$\alpha_{1 m}=24^{\circ}$

$\tan \alpha_{1 r}=1.4 \times \tan 24^{\circ}=0.6233$

$\alpha_{1 r}=\tan ^{-1} 0.6233$

$\alpha_{1 r}=32^{\circ}$

$\tan \alpha_{1 t}=\frac{r_{r}}{r_{t}} \tan \alpha_{1 r}$

$\tan \alpha_{1 t}=\frac{1}{1.8} 0.6233=0.3463$

$\alpha_{1 t}=\tan ^{-1} 0.3463$

www.ijasre.net 
$\alpha_{1 t}=19.1^{\circ}$

Efflux angle at the root $=32^{\circ}$

Efflux angle at the tip $=19.1^{\circ}$

\section{WORK DONE ON THE TURBINE BLADE}

$C_{w 2}=\frac{r_{m} \times C_{a 2}}{r_{r} \times \tan \alpha_{2 m}}$

$C_{w 2}=\frac{1.4 \times 350}{\tan 24^{\circ}}$

$C_{w 2}=1100.6 \mathrm{~m} / \mathrm{s}$

$W=m \times U \times C_{w 2}$

$W=25 \times 500 \times 1100.6=13,757,500 W$

$W=13,757.5 \mathrm{~kW}$

Table 1.0 Show the summary of the stage calculation

\begin{tabular}{|l|l|l|}
\hline Stages & $\Delta T_{0 s}(\mathrm{~K})$ & \\
\hline 1 & & \multicolumn{1}{c|}{$\eta_{t t}$} \\
\hline 2 & 485.8 & 0.99 \\
\hline 3 & 492.3 & 0.97 \\
\hline 4 & 508.6 & 0.94 \\
\hline 5 & 513.8 & 0.93 \\
\hline
\end{tabular}

\section{CONCLUSION}

The performance of an axial flow turbine depends on its application. For turbine to transmit high torque, the blades must be long and have large chords that are adequately strong.

For maximum efficiency, the whirl component $C_{w 3}=0$ in which case the absolute velocity at exit is axial and then $C_{3}=C_{a 3}$ When the value of $\Phi$ and $\psi$ are low, it means that the gas velocity is low with reduced friction loss. For gas turbine used in aircraft engine, the primary consideration is to have minimum weight and small frontal area. It is necessary for tradeoff, to used higher value of $\Phi$ and $\psi$ to design aircraft turbine engine, but in expense of engine efficiency. At high $\psi$, less stage are required for overall turbine output, while at high $\Phi$, small turbine annulus area for a given mass flow. 


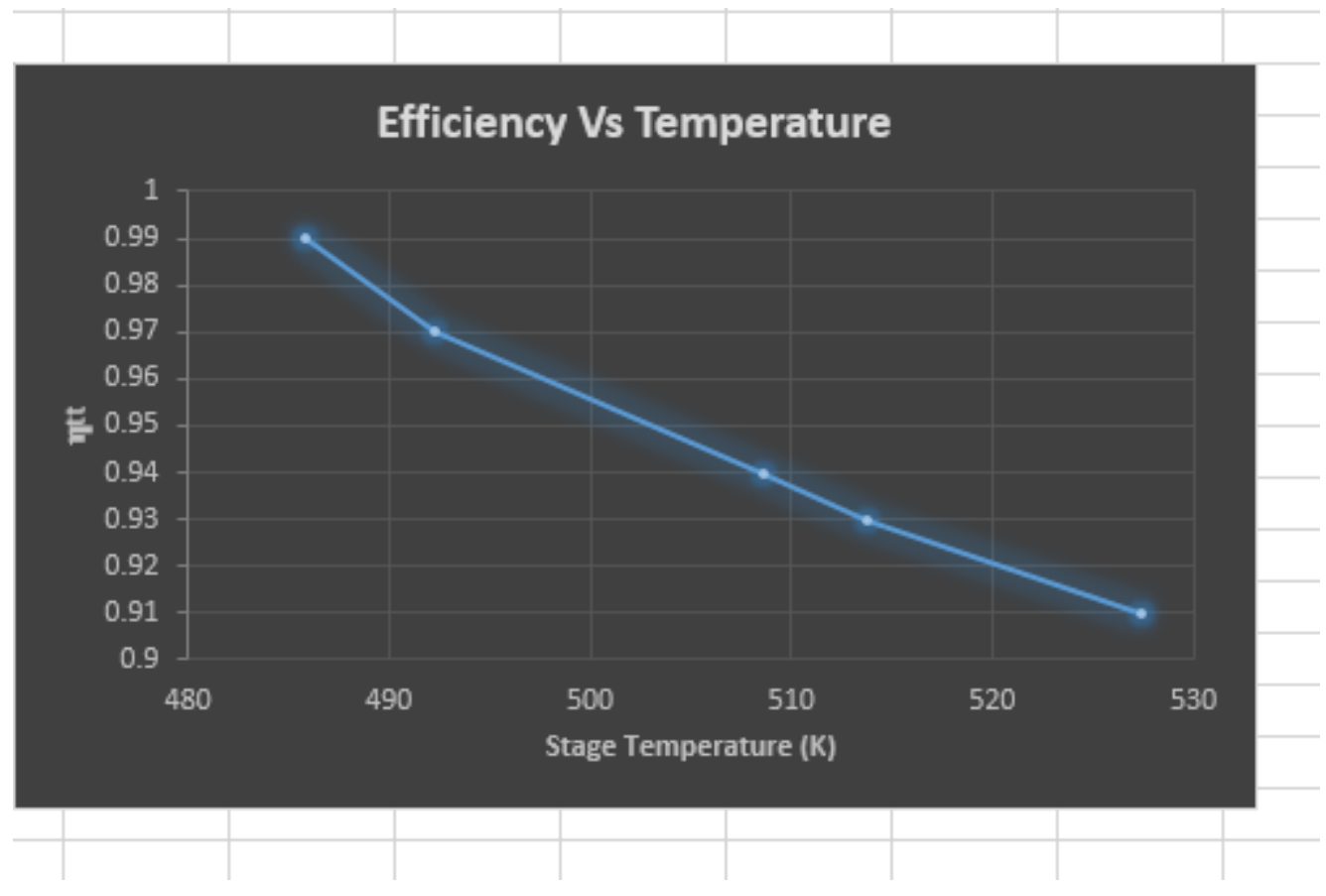

Figure 4.0 showing graph of Efficiency Vs temperature

The graph shown in figure 3.3 show how stage temperature varies with total-to-total efficency. The stage temperature, the lower the total-to-total efficiency of the axial flow turbine.

The rtesults obtained from this research, can be validated with simulation.

\section{REFERENCE}

1. H. I. H.Saravanamuttoo, et al. "Gas Turbine Theory". $7^{\text {th }}$ Edition, 2017.

2. H. Philip, and P. Carl "Mechanics and Thermodynamics of Propulsion". $2^{\text {nd }}$ edition. 2014.

3. S.R.G. Rama, and A. K. Aijaz “Turbomachinery: Design and Theory”. 2003.

4. Avwunuketa et al "Performance Evaluation of Axial Flow Compressor using Stages Characteristics". International Journal of Thermal Engineering (IJTE), 2019.

5. T. D. Eastop, and A. McConkey “Applied Thermodynamics for Engineering Technologist”. 5th Edition.1998

6. R.K. Turton "Principles of Turbomachinery", 2nd Edition, 1995.

7. S.L. Dixon "Fluid Mechanics and Thermodynamics of Turbomachinery", 4th Edition.1993

8. D. G. Wilson "Design of High Efficiency Turbomachinery and Gas turbines".1984.

9. A. Avwunuketa, et al "Aircraft Auxiliary Power unit (APU) Condition Monitoring”. International Journal of Aerospace and Mechanical Engineering (IJAME) 2019.

10. J. Seddon, and E.L. Goldsmith "Intake Aerodynamics". 1985

11. J.D. Enyia, et al "Industrial Gas Turbine On-Line Compressor Washing for Power Generation". International Journal of Engineering Research \& Technology (IJERT) 2015.

12. A. Avwunuketa,et al "Optimizing axial Flow Turbomachinery Rotor blade for enabling Variable Speed Gas Turbine Engine Performance”. International Journal of Engineering Science and Computing (IJESC) 2019.

13. W.R. Hawthorne, et al "Aerodynamics of Turbines and Compressors".1964

14. G.C. Oates “Aerothermodynamics of Gas Turbine and Rocket Propulsion”.1984

15. G.F.C. Rogers and Y.R .Mayhew "Engineering Thermodynamics, Works and Heat Transfer". $4{ }^{\text {th }}$ Edition, 1992.

16. M. P. Boyce Transonic Axial-Flow Compressor. ASM Paper No. 67-GT-47.

17. D. G. Ainley and G. C. R. Mathieson "A Method of Performance Estimation for axial-Flow turbines".1951

18. B.T. Lebele-Allawa "Rotor-Blades Profile Influence on a Gas Turbines Compressor Effectiveness" Applied Energy, 2008.

19. M.P. Boyce "Gas Turbine Engineering Handbook", $2^{\text {nd }}$ Edition.2003.

20. W. W. Bathie "Fundamentals of Gas Turbines". $2^{\text {nd }}$ Edition. 1995.

21. M. L. Mathur and R. P. Shama "Gas Turbine and Jet \& Rocket Propulsion", $4^{\text {th }}$ Edition.2014

22. A. M. Y. Razak "Industrial Gas Turbines, Performance and Operability".2007

23. P. P. Walsh and P. Fletcher "Gas Turbine Performance", $2^{\text {nd }}$ Edition.2004 